Plant Tissue Cult. \& Biotech. 29(2): 277-284, 2019 (December)

CBangladesh Assoc. for Plant Tissue Culture \& Biotechnology

$\overline{\mathrm{PTC} \& \mathrm{~B}}$

\title{
In Vitro Micropropagation of Stevia rebaudiana Bertoni
}

\section{Sabina Yesmin*}

Plant Biotechnology Division, National Institute of Biotechnology, Ganakbari, Ashulia, Savar, Dhaka-1349, Bangladesh

Key words: Stevia rebaudiana, Nodal segments, Shoot tips, Micropropagation, Acclimatization

\begin{abstract}
Multiple shoots were obtained from both shoot tips and nodal segments cultured on MS fortified with different concentrations of BAP and Kn singly or in combination with low concentration of NAA. Maximum number of shoots $(9.28 \pm 0.61)$ were found on MS supplemented with $1.5 \mathrm{mg} / \mathrm{BAP}$ and $05 \mathrm{mg} / \mathrm{NAA}$. In vitro regenerated shoots were separated and transferred onto half and full-strength MS supplemented with different concentration of IBA, IAA and NAA for root induction. Full strength MS containing 0.2 mg/ IBA was found to be best for root induction where $93.33 \%$ shoots were rooted. In vitro regenerated plants grew normally without showing any morphological variation and flowered after 40 days of transplantation.
\end{abstract}

\section{Introduction}

Stevia rebaudiana Bertoni, commonly known as sweet herb or honey leaf is a small branched, semi-bushy, perennial shrub belongs to Asteraceae. Stevia is originated from the highlands of Paraguay and sections of Argentina and Brazil (Robinson 1930). Dr. Moises Santiago Bertoni, a South American Natural Scientist revealed stevia in 1888 and described its taxonomy (Sakaguchi and Kan 1982). This species is adapted to moist area and needs continuously wet places (Antonie and Greenwood 2000). The plant height of stevia is about $50-65 \mathrm{~cm}$, leaves are sessile, oppositely arranged lanceolate to oblanceolate leaves, serrated towards apex. Stevia is one of the genera of 154 members of the family of Asteraceae (Robinson 1930).

Stevia has medicinal properties which are used against antibacterial, anticandidal, antifungal, antiviral, cardio tonic, diuretic, hypoglycemic, vasodilator (Jitendra et al. 2012). Leaves of stevia are the source of diterpene glycosides, stevioside and rebaudioside. Stevioside is regarded as a valuable natural sweetening agent because of its relatively good taste and chemical stability (Yamada et al. 1985).

*E-mail: <sabinanib79@gmail.com>.

DOI: https://doi.org/10.3329/ptcb.v29i2.44516 
This herb is a natural sweetener plant, estimated to be 300 times sweeter than sugarcane (Soejarto et al. 1982 and Yoshida 1986). The nature of this sweetening agents is non-caloric and safely consumed by diabetic patients with hyperglycemia and overweight persons aiming to lose weight (Das et al. 2011). Leaves of stevia plants can be used directly as a sweetening agent or stevioside can be extracted in pure form and then used as a sweetener. To decrease sugar consumption dried leaves of stevia or extracted steveoside could be used with foodstuffs and beverages (Modi et al. 2011). Stevia is used as a table top sweetener, in soft drink, fruit juices, ice creams, yoghurts, sherbets, pastries, pies, baking, jams, sauces, pickles, jellies, desserts, chewing gum, candies, confectionary goods, seafoods and vegetables (Karim et al. 2008). Recently, stevia has been commercially cultivated in several countries in the world like, Brazil, Korea, Japan, Mexico, United States, Indonesia, Tanzania and Canada (Shock 1982, Saxena and Ming 1988, Brandle and Rosa 1992, Fors 1995) for food and pharmaceuticals products.

The traditional methods of stevia mass multiplication or propagation is time consuming, impulsive, undependable and less productive. The seeds of stevia show very little rate of germination and it is difficult to harvest as well as preserve seed for large or commercial cultivation. Conventional propagation through clonal cuttings is inadequate by smaller number of individuals and insufficient to meet the demand (Sakaguchi and Kan 1982). There has been an increased interest in in vitro culture systems which offer a feasible tool for mass multiplication and germplasm preservation of commercially important medicinal plants. Therefore, it is imperative to develop an efficient micropropagation technique for stevia for rapid multiplication. In Bangladesh there are a few reports on the establishment of micropropagation protocol for stevia (Karim et al. 2008). The present investigation aims at developing a simple, rapid, efficient, high frequency and reproducible in vitro micropropagation system from shoot tips and nodal explants with higher existence rate so as to produce to true-to-type plants for potential application in large-scale proliferation.

\section{Materials and Methods}

The experiments were carried out in the Plant Biotechnology Division of National Institute of Biotechnology of Bangladesh. Stevia rebaudiana Bertoni was collected from the medicinal plant garden of National Institute of Biotechnology campus. Nodal segments and shoot tips were used for this purpose. The nodal segments $(1.0-1.5 \mathrm{~cm})$ and shoot tips $(2.0-3.0 \mathrm{~mm})$ were excised and thoroughly washed under running tap water for 30 $\mathrm{min}$. Then they were treated with mild detergent followed by rinsing several times with distilled water. The explants were dipped in $0.2 \%$ antifungal Bavistin for $3.0 \mathrm{~min}$ and again washed 4 - 5 times with distilled water. Further sterilization was done in laminar air flow cabinet under aseptic conditions. The explants were dipped in $70 \%(\mathrm{v} / \mathrm{N})$ ethanol for $1.0 \mathrm{~min}$ and then washed three times with sterilized distilled water. For surface sterilization, the explants were dipped in $0.1 \%$ aqueous solution $(\mathrm{w} / \mathrm{N})$ of $\mathrm{HgCl} 2$ for $2-3$ 
min. Finally, they were washed with sterilized distilled water for $5-6$ times, till the sterilant were removed completely. The nodal segments and shoot tips were then trimmed/cut at both ends prior to inoculation on culture media. The explants were cultured on MS with 3\% sucrose and supplemented with various concentrations of BAP and $\mathrm{Kn}(0.5-5.0 \mathrm{mg} \Lambda)$ alone or in combination with NAA $(0.2-0.5 \mathrm{mg} \Lambda)$. The $\mathrm{pH}$ was 5.8. The medium was gelled with $0.8 \%$ agar and autoclaved at $121^{\circ} \mathrm{C}$ for $20 \mathrm{~min}$.

After inoculation, all the cultures were incubated at $25 \pm 2^{\circ} \mathrm{C}$ and $16 / 8 \mathrm{hrs}$ (light/dark) photoperiod with 3000 lux intensity illumination provided by cool-white fluorescent tubes. After three-four weeks the explants were subcultured at a regular interval of 10 15 days. For root induction, $3-4 \mathrm{~cm}$ long shoots were excised and transferred to half and full-strength MS with IBA, IAA and NAA (0.2- $0.5 \mathrm{mg} \Lambda$ ) alone. The rooted plantlets were removed from the culture vessels and rinsed with sterilized distilled water to remove all trace of medium attached to the roots. Then the rooted plantlets were transplanted in small plastic pots containing autoclaved garden soil and compost $(1: 1)$. In order to maintain a high humidity, the pots were then covered with transparent polythene bags and acclimatized in the growth room temperature $\left(25 \pm 2^{\circ} \mathrm{C}\right)$ for $2-3$ weeks. After 2 - 3 weeks, these pots were uncovered and then they were exposed to partial and then complete direct sun light. Finally, these hardened plantlets were transferred to the natural condition for their further growth and development.

\section{Results and Discussion}

Shoot tips and nodal segments were cultured on MS supplemented with different concentrations of BAP $(0.5-5.0 \mathrm{mg} /)$ and $\mathrm{Kn}(0.5-5.0 \mathrm{mg} \Lambda)$ alone and BAP with different concentrations of NAA $(0.2-0.5 \mathrm{mg} \Lambda)$ for multiple shoot formation. The shoot tips and nodal segments explants were found to be swollen and they produced two to five shoots within three to four weeks after inoculation on MS supplemented with BAP and $\mathrm{Kn}$ singly but the number of shoots increased up to nine when the nodal explants were inoculated in MS with $1.5 \mathrm{mg} / \mathrm{BAP}$ and $0.5 \mathrm{mg} / \mathrm{NAA}$ (Table 1). In case of BAP the maximum number of shoots in nodal explants were obtained in MS with $1.5 \mathrm{mg} \Lambda$ BAP. The highest $(68 \%)$ number of explants responded for shoot induction. The maximum number $(4.26 \pm 0.57)$ of shoots /explants and the average length $(1.85 \pm 0.17 \mathrm{~cm})$ of shoots were recorded in this concentration (Fig. 1B). Initiation of shoot regeneration was started within 7 days after inoculation. The shoot tips explants were found less responsive on MS with different concentrations of BAP (Table 1). Previous workers (Karim et al. 2008, Ahmed et al. 2007, Jitendra et al. 2012, Namdari et al. 2015 and Alhady 2011) also reported the nodal segments as a highly efficient explant regarding shoot regeneration, proliferation and growth were obtained in stevia micropropagation. However, the shoot tip explants produced highest percentage (89) of responsive explants, maximum number $(6.53 \pm 0.49)$ of shoots/explant with an average length of shoots $(1.27 \pm 0.10 \mathrm{~cm})$ in MS with $2.0 \mathrm{mg} / \mathrm{Kn}$ (Fig. 1A, Table 1). After four weeks these shoots were subcultured in 
same regeneration medium and they produced stunted and bushy shoots (Fig. 1D). This result was not identical with previous report (Das et al. 2011) where 11.0 shoots/explant with average length $(11.13 \pm 0.2 \mathrm{~cm})$ were induced in $2.0 \mathrm{mg} / \mathrm{Kn}$. Hassanen and Khalil (2013) also reported a highly efficient and reproducible (43.9 shoots/explant) in vitro regeneration system for stevia through shoot tip culture on MS + 2.0 mg 1 BAP with low survival rate.

Table 1. Effects of BAP, Kn and NAA on multiple shoot regeneration from shoot tips and nodal segments of Stevia rebaudiana.

\begin{tabular}{|c|c|c|c|c|c|c|c|c|}
\hline \multicolumn{3}{|c|}{$\begin{array}{l}\text { Growth regulators } \\
\qquad(\mathrm{mg} \Lambda)\end{array}$} & \multicolumn{3}{|c|}{$\begin{array}{l}\text { Shoot } \\
\text { tips }\end{array}$} & \multicolumn{3}{|c|}{$\begin{array}{c}\text { Nodal } \\
\text { segments }\end{array}$} \\
\hline BAP & $\mathrm{Kn}$ & NAA & $\begin{array}{l}\quad \% \text { of } \\
\text { responsive } \\
\text { explants }\end{array}$ & $\begin{array}{c}\text { Mean no. of } \\
\text { shoots/ } \\
\text { explant }( \pm S E)\end{array}$ & $\begin{array}{l}\text { Length of } \\
\text { shoots }(\mathrm{cm}) \\
\quad \pm \mathrm{SE}\end{array}$ & $\begin{array}{l}\text { \% of } \\
\text { responsive } \\
\text { explants }\end{array}$ & $\begin{array}{c}\text { Mean no. of } \\
\text { shoots/ } \\
\text { explant }( \pm S E)\end{array}$ & $\begin{array}{l}\text { Length of } \\
\text { shoots }(\mathrm{cm}) \\
\quad \pm \mathrm{SE}\end{array}$ \\
\hline 0.5 & - & - & 38 & $1.45 \pm 0.33$ & $0.71 \pm 0.06$ & 51 & $1.90 \pm 0.42$ & $1.15 \pm 0.12$ \\
\hline 1.0 & - & - & 44 & $1.53 \pm 0.36$ & $1.03 \pm 0.12$ & 64 & $2.86 \pm 0.38$ & $1.45 \pm 0.14$ \\
\hline 1.5 & - & - & 64 & $2.13 \pm 0.22$ & $1.09 \pm 0.12$ & 68 & $4.26 \pm 0.57$ & $1.85 \pm 0.17$ \\
\hline 2.0 & - & - & 58 & $2.06 \pm 0.38$ & $1.16 \pm 0.12$ & 67 & $2.46 \pm 0.53$ & $2.04 \pm 0.15$ \\
\hline 3.0 & - & - & 51 & $1.53 \pm 0.37$ & $1.01 \pm 0.14$ & 60 & $2.00 \pm 0.44$ & $1.8 \pm 0.16$ \\
\hline \multirow[t]{7}{*}{5.0} & - & - & 46 & $1.33 \pm 0.34$ & $1.02 \pm 0.07$ & 56 & $1.80 \pm 0.45$ & $1.05 \pm 0.05$ \\
\hline & 0.5 & - & 51 & $1.53 \pm 0.44$ & $0.78 \pm 0.05$ & 47 & $1.53 \pm 0.44$ & $1.94 \pm 0.15$ \\
\hline & 1.0 & - & 60 & $2.13 \pm 0.51$ & $1.07 \pm 0.12$ & 51 & $1.86 \pm 0.47$ & $2.11 \pm 0.11$ \\
\hline & 1.5 & - & 64 & $3.13 \pm 0.45$ & $1.18 \pm 0.13$ & 49 & $2.13 \pm 0.84$ & $2.28 \pm 0.13$ \\
\hline & 2.0 & - & 89 & $6.53 \pm 0.49$ & $1.27 \pm 0.10$ & 58 & $2.64 \pm 0.61$ & $2.52 \pm 0.10$ \\
\hline & 3.0 & - & 62 & $2.13 \pm 0.49$ & $0.91 \pm 0.08$ & 56 & $2.06 \pm 0.53$ & $1.43 \pm 0.14$ \\
\hline & 5.0 & - & 57 & $1.80 \pm 0.49$ & $0.95 \pm 0.09$ & 31 & $1.26 \pm 0.45$ & $1.21 \pm 0.14$ \\
\hline 1.0 & & 0.2 & 56 & $3.27 \pm 0.62$ & $1.23 \pm 0.11$ & 89 & $3.73 \pm 0.53$ & $2.18 \pm 0.12$ \\
\hline 1.5 & & 0.2 & 76 & $3.50 \pm 0.50$ & $1.33 \pm 0.10$ & 96 & $4.20 \pm 0.53$ & $2.29 \pm 0.10$ \\
\hline 2.0 & & 0.2 & 55 & $2.86 \pm 0.52$ & $0.96 \pm 0.07$ & 76 & $4.00 \pm 0.48$ & $2.35 \pm 0.12$ \\
\hline 1.0 & & 0.5 & 59 & $2.53 \pm 0.48$ & $1.25 \pm 0.10$ & 89 & $4.13 \pm 0.84$ & $2.95 \pm 0.16$ \\
\hline 1.5 & & 0.5 & 73 & $2.21 \pm 0.51$ & $1.36 \pm 0.10$ & 96 & $9.28 \pm 0.61$ & $3.11 \pm 0.13$ \\
\hline 2.0 & & 0.5 & 71 & $2.53 \pm 0.53$ & $1.00 \pm 0.06$ & 76 & $4.80 \pm 0.63$ & $3.06 \pm 0.15$ \\
\hline
\end{tabular}

To evaluate the combined effect of various concentrations and combinations of BAP and NAA on MS, shoot tips and nodal explants of stevia were cultured for multiple shoot induction. In the present investigations, the nodal explants grew profusely in MS with 1.5 $\mathrm{mg} / \mathrm{BAP}$ and $0.5 \mathrm{mg} / \mathrm{NAA}$ among the three different media. The explants (nodal segments) started in producing shoots within five days in MS with $1.5 \mathrm{mg} / \mathrm{BAP}$ and 0.5 mg 1 NAA. The highest percentage of responsive explants (96) was observed in MS + 1.5 
$\mathrm{mg} / \mathrm{BAP}+0.5 \mathrm{mg} / \mathrm{NAA}$. The maximum number $(9.28 \pm 0.61)$ of shoots per explant and shoot length $(3.11 \pm 0.13 \mathrm{~cm})$ were found in this medium (Fig. 1C). Thiyagarajan and Venkatachalam (2012) also reported that MS with $1.0 \mathrm{mg} / \mathrm{BAP}$ and $0.5 \mathrm{mg} / \mathrm{IAA}$ was most effective for shoot induction in stevia from in vitro derived shoot bud. In the present study in vitro raised small shoots were subcultured in the same medium the number of multiple shoots increased but the shoot length, leaves size and number of leaves reduced. Repeated subcultured of microshoots in the same medium at 15 days intervals resulted vigorous shoot proliferation in which about 140 shoots were obtained per culture within 12 weeks (Fig. 1E). For shoot elongation and increased the length of shoot, size of leaves, number of leaves, the regenerated microshoots were transferred into MS medium without plant growth regulator. Leaves of regenerated shoots expanded, turned deep green colour from light green and thickness of stem increased in MS (Fig. 1F). Nodal cutting from these in vitro raised elongated shoots were further cultured and maintained in same medium for further shoot multiplication. Almost similar results were also described by Hassan et al. (2009) in Ficus religiosa a multiuse medicinal plant.

Table 2. Effects of growth regulators on in vitro root induction in regenerated shoots of Stevia rebaudiana on half and full-strength MS.

\begin{tabular}{cccccccc}
\hline $\begin{array}{c}\text { MS } \\
\text { strength }\end{array}$ & IBA & IAA & NAA & $\begin{array}{c}\text { Rooted } \\
\text { shoots }(\%)\end{array}$ & $\begin{array}{c}\text { Initiation of } \\
\text { roots (days) }\end{array}$ & $\begin{array}{c}\text { Mean no. of } \\
\text { roots/shoot }( \pm \text { SE })\end{array}$ & $\begin{array}{c}\text { Mean Length of } \\
\text { roots }(\mathrm{cm})( \pm \text { SE })\end{array}$ \\
\hline $1 / 2$ MS & - & - & & 40 & $15-16$ & $2.10 \pm 0.23$ & $3.31 \pm 0.16$ \\
$1 / 2$ MS & 0.2 & & & 47 & $13-14$ & $3.60 \pm 0.31$ & $4.89 \pm 0.24$ \\
$1 / 2$ MS & 0.5 & & & 40 & $16-17$ & $3.10 \pm 0.43$ & $4.30 \pm 0.18$ \\
$1 / 2$ MS & & 0.2 & & 53 & $14-15$ & $2.20 \pm 0.25$ & $3.71 \pm 0.24$ \\
$1 / 2$ MS & & 0.5 & & 40 & $17-18$ & $2.70 \pm 0.42$ & $3.60 \pm 0.25$ \\
$1 / 2$ MS & & & 0.2 & 33 & $15-16$ & $2.40 \pm 0.31$ & $3.39 \pm 0.23$ \\
$1 / 2$ MS & & & 0.5 & 40 & $19-20$ & $2.10 \pm 0.23$ & $3.72 \pm 0.20$ \\
MS & - & - & - & 53 & $16-17$ & $2.90 \pm 0.23$ & $4.26 \pm 0.17$ \\
MS & $\mathbf{0 . 2}$ & & & $\mathbf{9 3}$ & $\mathbf{1 0 - 1 2}$ & $4.30 \pm \mathbf{0 . 3 0}$ & $4.85 \pm \mathbf{0 . 2 5}$ \\
MS & 0.5 & & & 60 & $15-16$ & $3.80 \pm 0.39$ & $4.02 \pm 0.19$ \\
MS & & $\mathbf{0 . 2}$ & & $\mathbf{7 3}$ & $\mathbf{1 3 - 1 4}$ & $4.00 \pm 0.33$ & $3.78 \pm \mathbf{0 . 2 2}$ \\
MS & & 0.5 & & 53 & $16-17$ & $3.50 \pm 0.40$ & $3.91 \pm 0.21$ \\
MS & & & 0.2 & 53 & $15-16$ & $2.70 \pm 0.37$ & $3.97 \pm 0.23$ \\
MS & & & 0.5 & 33 & $15-16$ & $1.80 \pm 0.25$ & $3.64 \pm 0.17$ \\
\hline
\end{tabular}

Regenerated healthy shoots of $3-4 \mathrm{~cm}$ length was separated from the cluster of shoots and cultured on half and full strength of MS with different concentrations of IBA, IAA and NAA $(0.2-0.5 \mathrm{mg} \Lambda)$ singly. The results of these experiments are presented in Table 2. Among IBA, IAA and NAA the best root induction and development was found in MS with $0.2 \mathrm{mg} / \mathrm{IBA}$. The highest percentage (93) of root formation, maximum 
number of roots $(4.30 \pm 0.30)$ and highest length $(4.85 \pm 0.25)$ of roots were recorded in this medium within three to four weeks of inoculation (Fig. 1G). Several previous investigators (Karim et al. 2008 and Jitendra et al. 2012) reported root induction in stevia by using low concentrations of IBA in MS. Root induction in other medicinal plants was reported (Das et al. 2008, Karthikeyan et al. 2009 and Hossain et al. 2013) by using IBA in MS and modified MS. In the present investigation IAA and NAA were less effective for root induction in stevia.

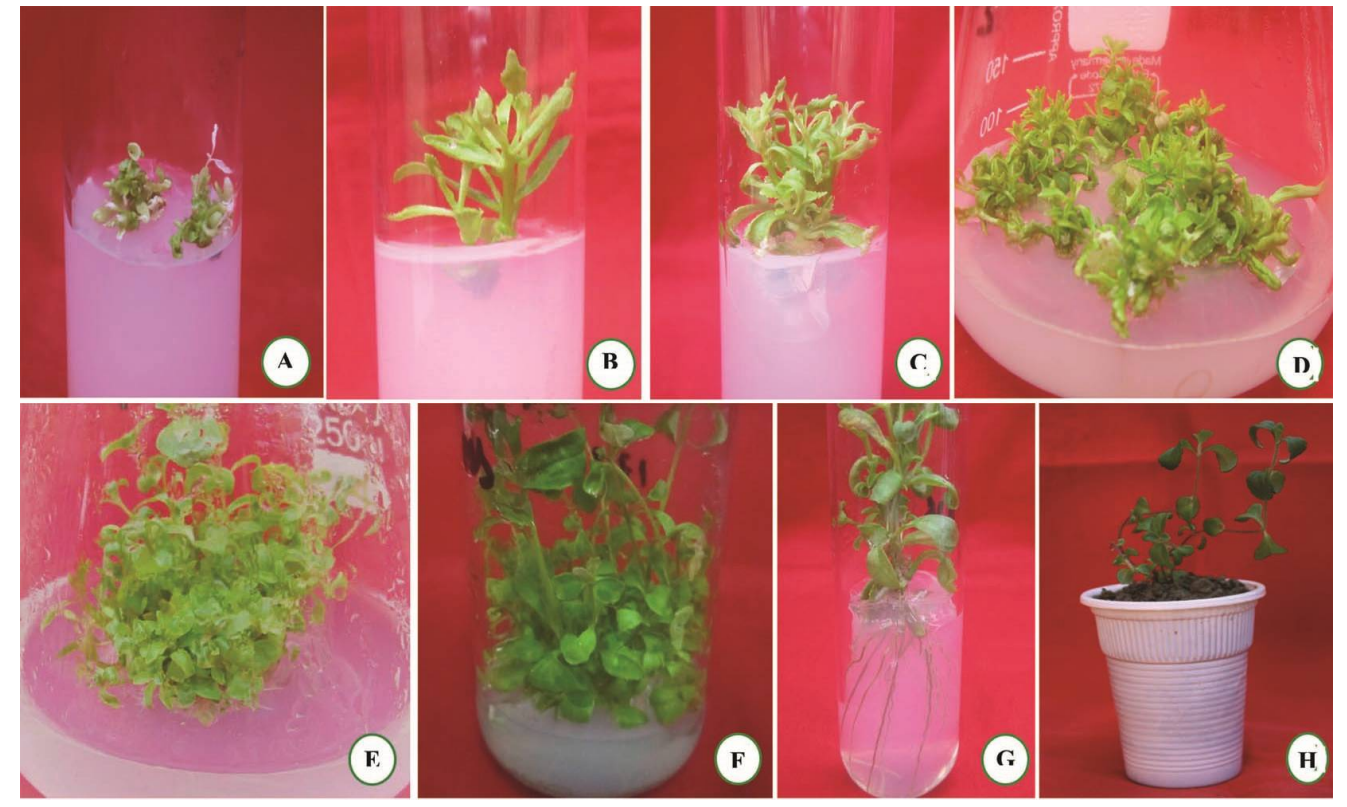

Fig. 1 (A-H). Shoot proliferation of stevia from shoot tip and nodal segment explants. A. Induction of shoots from shoot tips explants. B, C. Initiation of multiple shoots from nodal explants. D. Shoot tips explants in same regeneration medium after eight weeks of culture. E. Shoots from nodal explants in same regeneration medium after eight weeks of culture. F. Elongation and proliferation of in vitro shoots on MS after ten weeks of culture in case of both explants. G. Rooting of in vitro regenerated shoots. H. Plantlets in small plastic pots containing sterilized soil.

After adequate growth of roots at the basal part of regenerated shoots, the rooted plantlets were transferred to small plastic pots containing sterilized soil (Fig. 1H). Following proper acclimatization plantlets were transferred to nethouse in large earthen pots containing garden soil and $84 \%$ plants survived. These plantlets flowered within 40 days after transplantation.

\section{References}

Ahmed MB, Salahin R, Karim R, Razvy MA and Hannan MM (2007) An efficient method for in vitro clonal propagation of a newly introduced sweetener plant (Stevia rebaudiana Bertoni.) in Bangladesh. Am. Eurasian J. Sci. Res. 2:121-125. 
In Vitro Micropropagation of Stevia rebaudiana

Alhady MRAA (2011) Micropropagation of Stevia rebaudiana Bertoni - A new sweetening crop in Egypt. Global Journal of Biotechnology \& Biochemistry 6(4): 178-182.

Antonie A and Greenwood R (2000) Stevia: A plant for sweetness? US Pharm. 25(12): 42-47.

Brandle JE and Rosa N (1992) Heritability of yield, leaf-steam ratio and stevioside content estimated from a landrace cultivar of Stevia rebaudiana Bertoni. Can. J. Plant Sci. 72: 1263-1266.

Das R, Hasan MF, Hossain MS and Rahman M (2008) Micropropagation of Centella asiatica L. an important medicinal herb. Progress. Agric. 19(2): 51- 56.

Das A, Gantait S and Mandal N (2011) Micropropagation of an elite medicinal plant: Stevia rebaudiana Bert. Int. J Agric. Resech. 6 (1): 40-48.

Fors A (1995) A new character in the sweetener scenario. Sugar J. 58: 30.

Hassan AKMS, Afroz F, Jahan MAA and Khatun R (2009) In vitro regeneration through apical and axillary shoot proliferation of Ficus religiosa L. - a multi-purpose woody medicinal plant. Plant Tissue Cult. Biotech. 19(1): 71-78.

Hassanen SA and Khalil RMA (2013) Biotechnological studies for improving of Stevia (Stevia rebaudiana Bertoni.) in vitro plantlets. Middle-East J. of Sci. Res. 14 (1): 93-106.

Hossain MJ, Khaleda L and Al-Forkan M (2013) Development of an efficient in vitro micropropagation protocol for medicinally important plant Achyranthes bidentate Blume. J. of Pharmacognosy and Phytochemistry 2(4): 6-13.

Jitendra M, Monika S, Ratan SD, Priyanka G, Priyanka S and Kiran DJ (2012) Micropropagation of an anti-diabetic plant - Stevia rebaudiana Bertoni, (Natural Sweetener) in Hadoti region of south-east Rajasthan, India. ISCA Journal of Biological Sciences 1(3): 37-42.

Karthikeyan K, Chandran C and Kulothungan S (2009) Rapid clonal multiplication through in vitro axillary shoot proliferation of Centella asiatica L. Indian Journal of Biotechnology 8: 232-235.

Karim MA, Jannat R, Rahman MS and Haque MS (2008) Micropropagation of stevia plant from nodal segments. Progress. Agric. 19(2): 21-26.

Modi AR, Shukla YM, Litoriya NS, Patel NJ and Narayanan S (2011) Effect of gibberellic acid foliar spray on growth parameters and stevioside content of ex vitro grown plants of Stevia rebaudiana Bertoni. Med. Plants 3: 157-160.

Namdari N, Shooshtari L and Qaderi A (2015) In vitro micropropagation of Stevia rebaudiana Bertoni. Biological Forum-An International Journal 7(1): 1750-1754.

Robinson BL (1930) Contributions from the Grey Herbarium of Harvard University. The Grey Herbarium of Harvard University, Cambridge, USA.

Sakaguchi M and Kan T (1982) Japanese researches on Stevia rebaudiana Bertoni and stevioside. Ci Cult. 34:235-248.

Saxena NC and Ming LS (1988) Preliminary harvesting characteristics of stevia. Phys. Prop. Agric. Mar. Prod. 3:299-303.

Shock CC (1982) Rebaudi's stevia: natural non-caloric sweeteners. California Agric. 36: 4-5.

Soejarto DD, Kinghorn AD and Fransworth NR (1982) Potential sweetening agents of plant origin. III. Organoleptic evaluation of stevia leaf herbarium samples for sweetness. J. Nat. Prod. 45(5): 590-599.

Yamada A, Ohgaki S, Noda T and Shimizu M (1985) Chronic toxicity study of dietary stevia extracts in F-344 rats. J. Food Hyg. Soc. Japan 26: 169-183. 
Yoshida S (1986) Studies on the production of sweet substances in Stevia rebaudiana: I. Simple determination of sweet glucoside in stevia plant by thin layer chromate-scanner and their accumulation patterns with plant growth. Jap. J. Crop. Sci. 55(2): 189-195.

Thiyagarajan M and Venkatachalam P (2013) Large scale clonal propagation of Stevia rebaudiana (Bert.) for commercial application: Pharmaceutically important and antidiabetic medicinal herb. Industrial Crops and Products 37: 111-117.

(Manuscript received on 02 November, 2019; revised on 20 November, 2019) 